\title{
Physiological aspects of creating a flour polycomposite mixture for bread
}

\author{
Natalia Berezina ${ }^{1 *}$, Vladimir Masalov ${ }^{1}$, Nina Pervykh ${ }^{1}$ and Evgenia Khmeleva $^{2}$ \\ ${ }^{1}$ Orel state agrarian university named after N.V. Parakhin 69, General Rodin Str., Orel, Russia \\ ${ }^{2}$ Orel State University named after I.S. Turgenev, 75, Komsomolskaya Str., Orel, Russia
}

\begin{abstract}
The paper presents the results of research aimed at creating a flour polycomposite mixture for bread with dry milk whey and dry rye fermented malt. Leading manufacturers of flour polycomposite mixtures offer products with similar chemical composition. Therefore, it is urgent to expand the range of new products with a balanced composition, which makes it possible to obtain bakery products of consistently high quality. By the methods of mathematical planning of the experiment using the sequential simplex method, the composition of the flour mixture was established, including: rye-wheat flour (60:40) - 93.5\%, dry fermented rye malt -3.75 , dry milk whey $-2.75 \%$. The analysis of finished products was carried out in terms of porosity and specific volume. The content of physiologically active substances in the finished bread was carried out by the calculation method. Bread made from a mixture of rye and wheat flour without additives was used as a control sample. Bread made from an optimal flour mixture has the best physical and chemical characteristics: specific volume $2.18 \mathrm{~g} / \mathrm{cm} 3$, porosity $70.1 \%$. The content of such minerals as $\mathrm{Ca}, \mathrm{Mg}$ and $\mathrm{P}$ in bread increased to $1.7,-4.5$ times, essential amino acids - to $5.2 \%$, and the amino acid rate increased to 1.0$18.6 \%$ compared to with control. At the same time, the content of the main nutrients (protein, fat and carbohydrates) in the product from the flour mixture is close to the control sample, and the energy value increased by $3.42 \mathrm{kcal}$.
\end{abstract}

\section{Introduction}

In recent years, there has been a tendency for the production of polycomposite flour mixtures that include, except flour, various non-traditional raw materials (seeds of various crops, organic acids, etc.). Flour multicomponent mixtures due to their low moisture content are characterized by high energy value, ease of transportation and storage, long shelf life [1]. Leading manufacturers of flour polycomposite mixtures [2] (Puratos, Alex-N, Melkom, etc.) offer products which composition is close to each other. In this regard, the expansion of the range of new products with a balanced composition, allowing to obtain bakery products of consistently high quality, is relevant.

The use of such raw materials as dry cheese whey and dry fermented rye malt in flour compositions due to the presence of functional components in them makes it possible to increase the digestibility of bread from a mixture of rye and wheat flour [3].

Dry cheese whey is a source of essential amino acids, especially such as tryptophan and lysine. It contains a significant amount of water-soluble proteins, milk sugar, and calcium and phosphate salts.
Dry cheese whey having a rich chemical composition makes it possible to shorten the technological process by activating the microflora of the dough and improve its taste and aroma characteristics. This increases the yield of bakery products and the shelf life of freshness.

Fermented dry rye malt is a traditionally used natural food product, widely used in the production of bread [4]. This component has a high biological value, contains deficient essential amino acids such as lysine and threonine, as well as easily digestible carbohydrates, and is rich in minerals. Malt has a positive effect on the structural and mechanical properties of the dough, which has a positive effect on the physical and chemical characteristics of the quality of bread. The presence of water-soluble substances in it increases the shelf life of the finished product.

\section{Materialandmethods}

The following raw materials were used in the work: peeled rye bakery flour according to GOST R 528092007, wheat flour for general purpose according to GOST $\mathrm{R}$ 52189-2003, fermented dry rye malt according to GOST R 52061-2003, dry cheese whey TU 9223-12304610209-2002, table food salt according to GOST R 51574-2018, pressed bakery yeast according to GOST

${ }^{*}$ Corresponding author: jrdan@yandex.ru 
54731-2011, citric acid according to GOST R 908-2004, drinking water according to SanPiN 2.1.4.1074-01. The quality of raw materials corresponded to the technical documentation.

The analysis of the finished products was carried out after their cooling down after 3 hours and no later than after 24 hours according to the following parameters: porosity according to GOST 5669-96; specific volume according to the methods given in [5]. The content of physiologically active substances in the finished bread was carried out by the calculation method, using tables of the chemical composition of the ingredients that make up the bread.

To optimize the composition of the flour mixture, the sequential simplex planning method was used. The first task in simplex planning is to construct the matrix of the original simplex - a table in which the coordinates of the experimental points are written.

There are various ways of orienting the simplex relative to the coordinate system, however, most often the center of the simplex is placed at the origin of coordinates, and the distance between the simplexes (the side of the simplex) is taken equal to one.

The first experiments are performed at the vertices of the simplex. The mixture included: a mixture of rye and wheat flour $(60: 40) \times 1$, dry cheese whey $\mathrm{x} 2$, fermented dry rye malt $x 3$. A universal matrix was used to determine the corresponding coded values of the factors (Table 1).

As a result, a chain of simplexes is formed, moving to the optimumsphere. The center of these simplexesmoves along a line close to the gradient (Fig. 1).

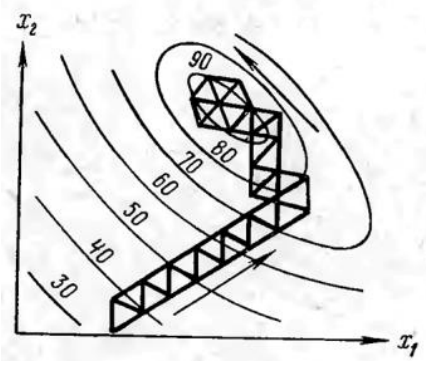

Fig. 1.A diagram of the motion of a simplex to the optimum region.

Table 1.Universal matrix of a simplex design.

\begin{tabular}{|c|c|c|c|c|c|c|c|}
\hline 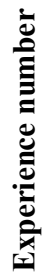 & 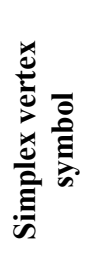 & $\mathbf{z}_{1}$ & $\mathbf{z}_{1}$ & $\mathbf{z}_{1}$ & .. & $\mathbf{Z}_{\mathrm{n}-\mathbf{1}}$ & $\mathbf{z}_{\mathbf{n}}$ \\
\hline 1 & $\mathrm{~A}$ & $\mathrm{x}_{1}$ & $\mathrm{x}_{2}$ & $\mathrm{X}_{3}$ & .. & $\mathrm{X}_{\mathrm{n}-1}$ & $\mathrm{x}_{\mathrm{n}}$ \\
\hline 2 & B & $\begin{array}{l}- \\
\mathrm{x}_{1}\end{array}$ & $\mathrm{x}_{2}$ & $\mathrm{x}_{3}$ & .. & $\mathrm{x}_{\mathrm{n}-1}$ & $\mathrm{x}_{\mathrm{n}}$ \\
\hline 3 & $\mathrm{C}$ & 0 & $-2 \mathrm{x}_{2}$ & $\mathrm{X}_{3}$ & .. & $\mathrm{X}_{\mathrm{n}-1}$ & $\mathrm{X}_{\mathrm{n}}$ \\
\hline 4 & $\mathrm{D}$ & 0 & 0 & $-3 x_{3}$ & ... & $\mathrm{X}_{\mathrm{n}-1}$ & $\mathrm{X}_{\mathrm{n}}$ \\
\hline$\ldots$ & $\ldots$ & $\ldots$ & $\ldots$ & $\ldots$ & .. & $\ldots$ & $\ldots$ \\
\hline $\mathrm{k}$ & $\mathrm{V}$ & 0 & 0 & 0 & .. & $\begin{array}{c}-(\mathrm{n}-1) \mathrm{x}_{\mathrm{n}}- \\
1\end{array}$ & $\mathrm{Xn}_{\mathrm{n}}$ \\
\hline
\end{tabular}

\begin{tabular}{|l|l|l|l|l|l|l|l|}
\hline $\mathrm{k}+1$ & $\mathrm{~W}$ & 0 & 0 & 0 & $\ldots$ & 0 & $-\mathrm{nx}_{\mathrm{n}}$ \\
\hline
\end{tabular}

The values of the constants xi are calculated by the formula (1):

$$
x_{i}=\sqrt{\frac{1}{2 i \cdot(i+1)}}
$$

From here

$$
\begin{aligned}
& \mathrm{z}_{1}=0,500 \\
& \mathrm{z}_{2}=0,289 \\
& \mathrm{z}_{3}=0,204 \\
& \mathrm{z}_{4}=0,158 \\
& \mathrm{z}_{5}=0,129 \\
& \mathrm{z} 6=0,109, \text { etc. }
\end{aligned}
$$

The vertices of the simplex are conventionally designated by capital Latin letters: A, B, C, D, etc.

After performing the first series of experiments, they find the vertex where the result of the experiment was the worst and "transfer" it to the opposite face of the simplex, as indicated above. The coordinates of the new vertex are found by the formula (2):

$$
Z_{i j}^{*}=\frac{2}{n} \cdot\left(Z_{i 1}+Z_{i 2}+\ldots . .+Z_{i, j-1}+Z_{i, j+1} \ldots . . Z_{i, n+1}\right)-Z_{i j}
$$

where $i$ is the factor number;

$j$ is the number of the experiment;

$n$ is the number of factors.

This formula can be expressed as follows: to determine the $i$-th coordinate of the new vertex of the simplex, you need to divide the double sum of all $i$-th coordinates of the remaining ("fixed") vertices by the number of factors and subtract the $i$-th coordinate of the previous value.

After each "transfer", an experiment is placed at a new vertex and the results of experiments are compared at all vertices of the simplex formed by the new vertex with the rest of the vertices not affected by this "transfer". After that, the vertex, in which the result was the worst, is again subjected to "transfer", and so on.

\section{Results and discussion}

It is known [6] that the dosage of dairy products in ryewheat bread should be no more than $4 \%$ of the flour mass. According to the literature [7], the dosage of fermented malt in flour mixtures is up to $10 \%$ of the flour mass. In this regard, when drawing up the experimental plan, the average dosage from the recommended norm was taken as the zero level: dry milk whey and malt - 5 and $2 \%$, respectively. The ingredients were added instead of the dry matter of rye-wheat flour, making the change in such a way that the amount of dry matter in the mixture was always $100 \%$.

The zero level and variation intervals for each factor are presented in Table 2 . 
Table 2.Zero level and variation intervals

\begin{tabular}{|l|l|l|}
\hline Factor & X & step \\
\hline dry fermented rye malt (x1) & 5 & 1.5 \\
\hline drycheesewhey (x2) & 2 & 1.5 \\
\hline
\end{tabular}

We use the data in Table 2 to encode factors. The natural values of the factors are calculated by the formulas (1) - (2):

Malt $($ step 1$)=5+1.5 \cdot 0.5=5.75$

Malt $($ step 2$)=5-1.5 * 0.5=4.25$

Malt (step 3) $=5$

Whey powder $($ step 1$)=2+1.5 \cdot 0.289=2.43$

Whey powder $($ step 2$)=2.43$

Whey powder $($ step 3$)=2+1.5 \cdot 0.578=2.87$
The content of dry substance in malt - 92\% (GOST R 52061-2003), in dry milk whey 97\% (TU 9223-12304610209-2002), in flour - 85\% (GOST R 52809-2007, GOST R 52189-2003).

Composing the proportion for the malt:

$100=92$

$\mathrm{X}=5.75$

Hence $X=5.75 \cdot 100 / 92=6.25$.

We do the rest of the calculations in the same way. The original simplex for $\mathrm{k}=2$ is shown in Table 3 .

To the resulting mixture was added compressed yeast in an amount of $2 \%$, citric acid $0.7 \%$ by weight of flour, water so that the moisture content of the dough was $50 \%$. The results of experiments at the points of the simplex are presented in Table 4.

Table 3.Initial simplex and working matrix for conducting experiments

\begin{tabular}{|c|c|c|c|c|c|c|c|c|c|c|c|}
\hline \multirow[b]{2}{*}{ 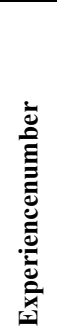 } & \multirow[b]{2}{*}{ 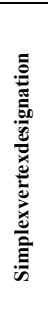 } & \multirow[t]{2}{*}{$\mathbf{x}_{1}$} & \multirow[t]{2}{*}{$\mathbf{x}_{2}$} & \multicolumn{4}{|c|}{$\begin{array}{c}\text { Content of mixture components in dry } \\
\text { substances }\end{array}$} & \multicolumn{4}{|c|}{$\begin{array}{l}\text { Content of mixture components } \\
\text { actually }\end{array}$} \\
\hline & & & & $\begin{array}{l}\text { dryferment } \\
\text { edryemalt }\end{array}$ & $\begin{array}{c}\text { drychees } \\
\text { ewhey }\end{array}$ & $\begin{array}{c}\text { a mixture } \\
\text { of rye } \\
\text { and } \\
\text { wheat } \\
\text { flour }\end{array}$ & $\begin{array}{c}\text { dryma } \\
\text { ttersu } \\
\mathrm{m}\end{array}$ & $\begin{array}{l}\text { dryfermentedrye } \\
\text { malt }\end{array}$ & $\begin{array}{l}\text { drychees } \\
\text { ewhey }\end{array}$ & $\begin{array}{l}\text { a mixture } \\
\text { of rye } \\
\text { and } \\
\text { wheat } \\
\text { flour }\end{array}$ & $\begin{array}{l}\text { the } \\
\text { sum of } \\
\text { the } \\
\text { mixtur } \\
\text { e } \\
\text { compo } \\
\text { nents }\end{array}$ \\
\hline 1 & $\mathrm{~A}$ & 0.5 & 0.289 & 5.75 & 2.43 & 91.82 & 100 & 6.25 & 2.50 & 108.02 & 116.77 \\
\hline 2 & $\mathrm{~B}$ & -0.5 & -0.289 & 4.25 & 2.43 & 93.32 & 100 & 4.62 & 2.50 & 109.78 & 116.90 \\
\hline 3 & $\mathrm{C}$ & 0 & 0.578 & 5.00 & 2.87 & 92.13 & 100 & 5.43 & 2.96 & 109.56 & 117.95 \\
\hline
\end{tabular}

Table 4. Results of experiments at points of a simplex

\begin{tabular}{|c|c|c|c|c|c|c|c|}
\hline \multirow{2}{*}{ 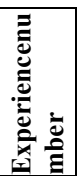 } & \multirow{2}{*}{\multicolumn{2}{|c|}{$\begin{array}{l}\text { Designation of the } \\
\text { simplex and its vertex } \\
\text { at which the } \\
\text { experiment is placed }\end{array}$}} & \multicolumn{3}{|c|}{ Content of mixture components in dry substances } & \multirow{3}{*}{ 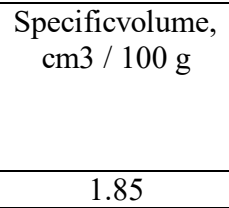 } & \multirow{3}{*}{$\begin{array}{c}\text { Porosity, } \% \\
64.0\end{array}$} \\
\hline & & & dryfermentedryemalt & drycheesewhey & $\begin{array}{l}\text { a mixture } \\
\text { of rye and } \\
\text { wheat flour }\end{array}$ & & \\
\hline 1 & & A & 5.75 & 2.43 & 91.82 & & \\
\hline 2 & $\mathrm{ABC}$ & $\mathrm{B}$ & 4.25 & 2.43 & 93.32 & 1.75 & 67.0 \\
\hline 3 & & $\mathrm{C}$ & 5.00 & 2.87 & 92.13 & 1.92 & 68.0 \\
\hline 4 & $\mathrm{ABCD}$ & $\mathrm{D}$ & 3.5 & 2.87 & 93.63 & 1.56 & 55.4 \\
\hline 5 & $\mathrm{ABCD}^{\prime}$ & $\mathrm{D}^{\prime}$ & 4.35 & 2.49 & 93.16 & 1.64 & 63.4 \\
\hline 6 & ABCD" & D" & 4.07 & 3.15 & 92.78 & 2.18 & 70.1 \\
\hline 7 & $\mathrm{~A}^{\prime} \mathrm{BCD} \mathrm{C}^{\prime \prime}$ & $\mathrm{A}^{\prime}$ & 5.75 & 2.43 & 91.82 & 1.97 & 68.5 \\
\hline 8 & $\mathrm{~A}^{\prime} \mathrm{B}^{\prime} \mathrm{CD} \mathrm{D}^{\prime \prime}$ & $\mathrm{B}^{\prime}$ & 4.25 & 2.43 & 92.78 & 1.95 & 69.0 \\
\hline
\end{tabular}

As can be seen from the data presented in table 4, the maximum optimization parameter was achieved in experiment 6 . Bread from the optimal mixture has the best physicochemical indicators, specific volume $2.18 \mathrm{~g} / \mathrm{cm} 3$, porosity $70.1 \%$.

The optimal composition of the flour mixture includes, $\%$ :

A mixture of rye and wheat flour 93.5

Fermented dry rye malt 3.75

Dry cheese whey 2.75

The preparation of bakery products from a flour mixture of the optimal composition was carried out in an accelerated manner using citric acid as an acidifier and compressed yeast as a leavening agent. A control sample consisting of a mixture of rye and wheat flour was made in the same way.

The content of proteins, carbohydrates and the energy value and energy value of bread are shown in Figure 2, the mineral composition is in Figure 3, the amino acid composition is in Figure 4, and the amino acid rate is in Figure 5.

It was found that in bread made from a flour mixture of optimal composition, the content of potassium, calcium and magnesium is $1.7,5.1$ and 4.5 times higher, respectively, the content of essential amino acids is $5.2 \%$, the amino acid rate is $1-18,6 \%$ compared to control, respectively. In this case, the content of proteins, carbohydrates and the energy value of the experimental sample have values close to the control. 


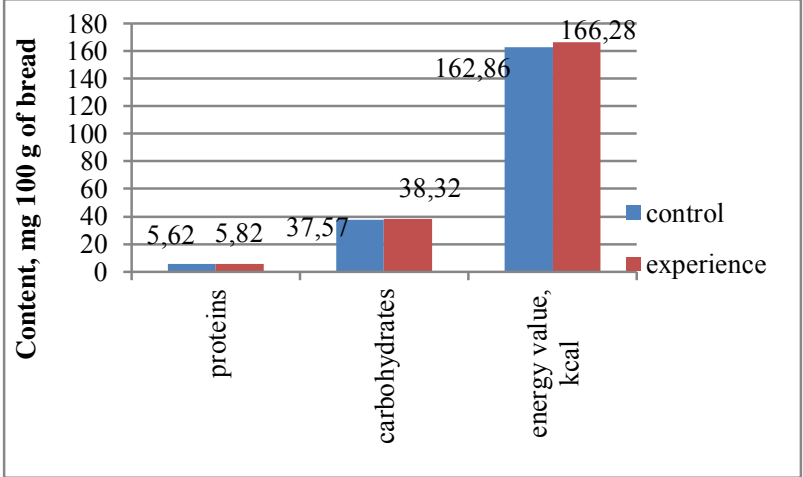

Fig. 2.The content of proteins, carbohydrates and the energy value of $100 \mathrm{~g}$ of bread.

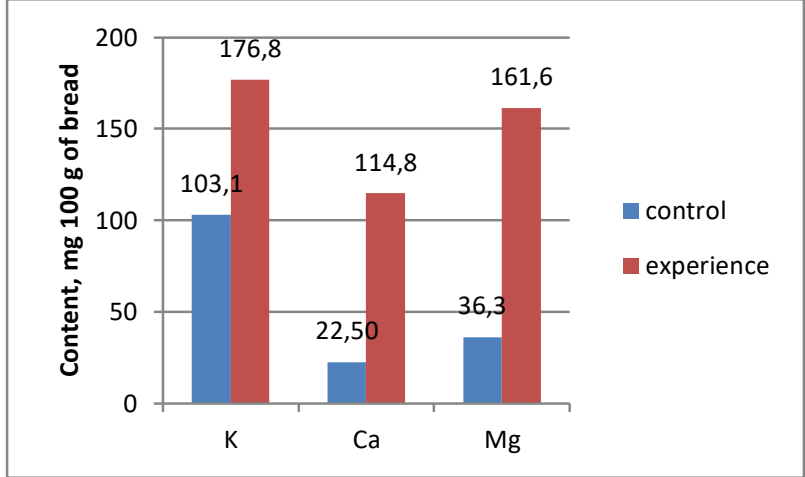

Fig. 3. The content of potassium, calcium and magnesium in $100 \mathrm{~g}$ of bread.

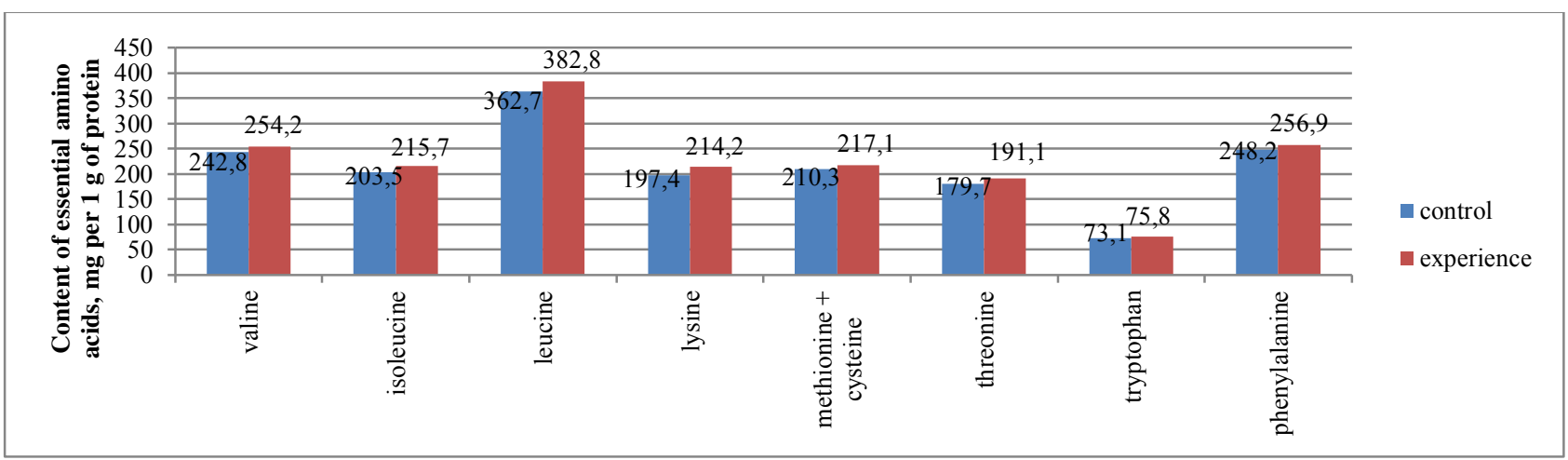

Fig. 4.Amino acid composition of bread.

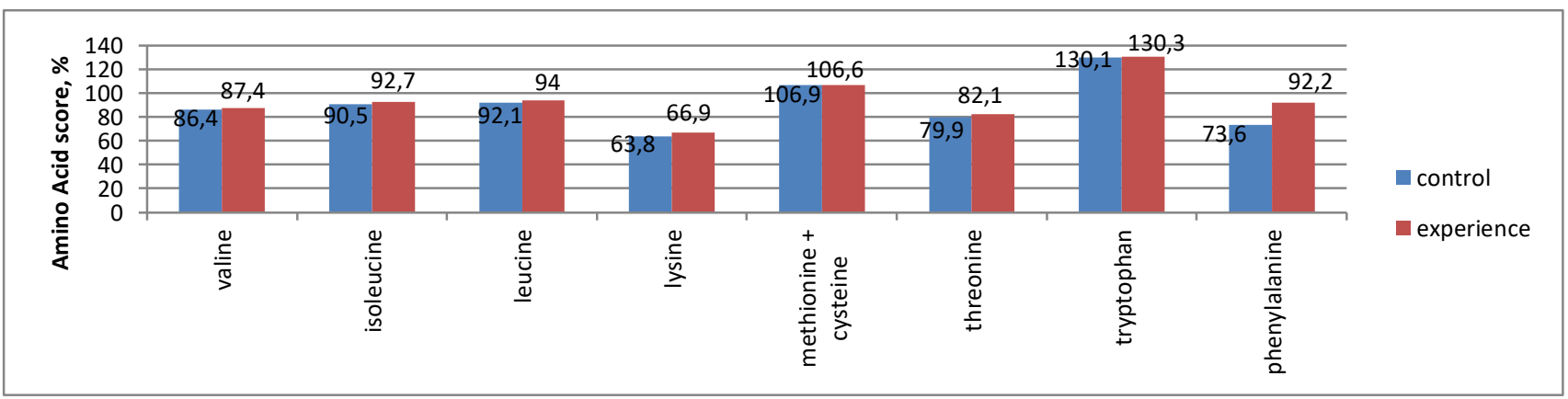

Fig. 5.Amino acid speed of bread.

\section{Conclusions}

Using the methods of mathematical planning of the experiment, the composition of the flour mixture was developed, including, \% rye-wheat flour (60:40) - 93.5, dry fermented rye malt -3.75 , dry cheese whey $-2.75 \%$. Bread made from a flour mixture contains an increased content of mineral elements, protein and essential amino acids in comparison with the control sample.

\section{References}

1. R.D. Polandova Collection of modern technologies of bakery products (Moscow printing house № 2, Moscow, 2008)
2. M.Sh. Arynbayeva, L.I. Kuznetsova, O.I. Parakhina, L.V. Usova. Current trends in science and technology, 1, 5 (2017)

3. B. Bigliardi, Trends in Food Science \& Technology 2, 11(2013).

4. W. Zhou, Y. H. Hui, Bakery Products Science and Technology(S.1., Wiley-Blackwell, 2014)

5. N.V. Labutina, S.Ya.Koryachkina, N.A. Berezina, E.V. Khmeleva. Control of raw materials, semifinished and finished bakery products (DeLi, Moscow, 2009)

6. B. S. Luh, Y. K. Liu, Rice 1, 24 (1991)

7. K. Dewettinck, Journal of Cereal Science 2, 14 (2008) 